\title{
Trabajo sexual y políticas antitrata: una justicia con qué perspectiva y de qué género
}

Marisa Silvana Tarantino

UNSAM/UBA

\section{Introducción}

A partir de la década del ochenta en el debate de nuestros feminismos, y desde los noventa en el escenario internacional, se puede apreciar un cambio sustancial del enfoque con el que se plantearon las distintas reivindicaciones del movimiento de mujeres. Tal como argumenta Trebisacce (2020), lo que previamente había sido nombrado en términos de opresión específica fue paulatinamente adoptando la palabra violencia como significante amo.

El nuevo paradigma de la violencia de género que, durante esa década, logró preponderancia en el discurso del feminismo institucionalizado, fue abrazando cada vez más la perspectiva de los derechos humanos, y con ello permitió hacer visible y disputar en la arena política un cúmulo de reivindicaciones históricas. Pero, al mismo tiempo, trajo algunas dificultades y límites: mientras lograba instalar las demandas históricas de las mujeres (cis), blancas, de clase media, occidentales y heterosexuales, que fueron las que lograron portar la voz del feminismo institucional, mantuvo a la vez soterradas u opacadas las de aquellas que por motivos de raza, clase, religión, nacionalidad u orientación sexual permanecieron en la marginalidad (Varela, 2015; Iglesias Skulj, 2018).

Por otra parte, la violencia como categoría de inteligibilidad de las demandas feministas, convocó cada vez más el paradigma punitivo y construyó la posición de las mujeres de acuerdo con la construcción de un sujeto-víctima unitario. El problema de este enfoque, tal como argumentó Tamar Pitch (2003 [1995]) es que, por un lado, produce un efecto de simplificación y despolitización de los conflictos; por el otro, construye subjetividades delineadas en términos binarios (víctimas-victimarios) y según responsabilidades que aparecen como producto de intencionalidades precisas. De esta manera, las demandas planteadas en términos de victimización, llevan implícita las de criminalización, porque tal forma de construcción de los problemas se realiza a la medida de la solución penal (Pitch, (2003 [1995]).

Las campañas contra la trata de personas impulsadas en el siglo XXI fueron una expresión de este paradigma victimista. Asimismo, el impacto que han tenido nos convoca a plantear la necesidad de un enfoque crítico que amplíe nuestras discusiones acerca de qué es lo que entendemos por perspectiva de género. 
Desde este marco me interesa abordar aquí la problemática del trabajo sexual y las políticas antitrata, precisamente como un aporte a este debate que quizá pueda impulsar alguna reflexión más profunda sobre la necesidad de una mejor y más extensa vocación pluralista y democrática para la Justicia.

\section{La campaña contra la trata en el nuevo milenio y su perspectiva neoabolicionista}

A fines de la década de los años 90, Estados Unidos de Norteamérica impulsó una campaña contra la trata de personas en el marco de su plan de lucha contra el crimen organizado, y con ello ejerció una gran influencia en el mundo occidental. En este sentido, la Convención de las Naciones Unidas contra la Delincuencia Organizada Transnacional (Palermo, Italia, diciembre de 2000), fue una instancia donde pudo evidenciarse esta (re)emergencia de la trata de personas como problema mundial.

En este escenario, el debate que se generó en torno a la definición de trata de personas que adoptaría el Protocolo de Palermo ${ }^{1}$ activó una fuerte confrontación entre grupos feministas de distintas trayectorias. Pero tal enfrentamiento no era nuevo, sino que reproducía las rupturas que habían caracterizado el debate en torno a la sexualidad, la pornografía y la prostitución ${ }^{2}$ durante la década de los años 70, y que habían dado origen a lo que se conoce como Sex Wars. ${ }^{3}$

El conjunto de postulados políticos, demandas feministas y propuestas de reformas de la legislación penal que caracterizaron el proceso de localización de la campaña antitrata en la Argentina son el fiel reflejo de la incidencia que ejerció aquel debate internacional en nuestro país y la política estadounidense que lo impulsó. La trata de personas fue presentada a partir de entonces en el escenario político - y también en el campo jurídico - como una tipología del crimen organizado, categoría no exenta de opacidades, pero que adquirió relevancia en la configuración de las políticas criminales en el mundo, sobre todo a partir de la "lucha contra el terrorismo" que planteó EE.UU., tras la caída de las torres gemelas en 2001.

La construcción del problema de la trata de mujeres tenía una larga historia que se remontaba a los debates jurídicos, biomédicos y políticos de fines del siglo XIX y principios del XX en torno al control de la prostitución, las enfermedades venéreas y, en especial, las preocupaciones y ansiedades sociales que despertaron las migraciones femeninas dirigidas al mercado sexual, y que dieron lugar a la construcción mítica de la trata de blancas (Doezema, 2010). Sin embargo, estos antecedentes solo fueron

1 Me refiero al "Protocolo Adicional para Prevenir, Reprimir y Sancionar la Trata de Personas, especialmente de Mujeres y Niños" perteneciente a la "Convención de las Naciones Unidas contra la Delincuencia Organizada Trasnacional" suscripta en Palermo, Italia, en el mes de diciembre del año 2000

2 Hablaré aquí de prostitución, sexo comercial y/o trabajo sexual para referirme a acuerdos voluntarios realizados entre personas adultas, que tienen por objeto la prestación de servicios sexuales a cambio de dinero. Es necesario asumir que esta definición es tan amplia como inestable, y no logra eludir el problema que genera la pretensión de abarcar bajo un mismo concepto, una serie de realidades y experiencias muy diversas. Como señala Laura Agustín (2009), la palabra prostitución es un término problemático porque suele remitir a formas estereotipadas del sexo comercial, que es un universo mucho más extenso que el que suele ser denotado: la industria del porno, la oferta sexual callejera, los servicios sexuales en departamentos privados, los servicios de sexo virtual, la asistencia sexual a personas con diversidad funcional/discapacidad, y muchas otras modalidades no podrían ser definidas o reducidas a una sola categoría.

3 Se conoce como Sex Wars la polémica que se dio en los EE.UU. durante los años 70 y 80 que tuvo como protagonistas a las máximas exponentes de una vertiente del feminismo radical que había impulsado el movimiento antipornografía. Su teoría partía de la idea de la sexualidad como pura dominación y opresión masculina. Este paradigma se enfrentó al feminismo prosexo, que cuestionó tal construcción de la sexualidad, a la que acusó de esencialista y biologicista (Lamas, 2016). 
recuperados de un modo tangencial; el problema de la trata logró instalarse en este siglo como si consistiera en una forma delictiva novedosa que había alcanzado una envergadura y gravedad que debía ser motivo de especial preocupación.

A través de una serie de presiones ejercidas por el Departamento de Estado de los EE.UU., con sus Trafficking in persons Reports, ${ }^{4} \mathrm{y}$ también como producto del trabajo de incidencia de la Organización Internacional para las Migraciones (OIM) en la campaña argentina (Varela, 2015), tuvo lugar un proceso político de discusión sobre los estándares exigidos por el Protocolo de Palermo y sobre el estatuto jurídico de la prostitución.

Este proceso de localización de la campaña antitrata en nuestro país despertó una profunda sensibilidad social que hizo proliferar opiniones muy negativas sobre la prostitución. Pero estas ya no se fundamentaron en los argumentos que habían sostenido históricamente su estigmatización (la idea de que la prostitución constituía una conducta inmoral), sino en una particular perspectiva de género, que asumió los

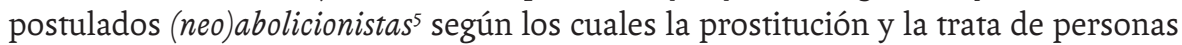
son conceptos asociados y expresan formas paradigmáticas de violencia de género y de violación de los derechos humanos de las mujeres y niñas.

La asunción de la perspectiva neoabolicionista en el debate y diseño de las políticas públicas argentinas contra la trata sexual y la preponderante apelación al poder simbólico del discurso penal han simplificado los términos en que se aborda el problema de la prostitución y, por lo tanto, no han podido dar cuenta de las múltiples variables que lo atraviesan, además de haber ocultado las profundas discrepancias que caracterizan el debate feminista sobre estos asuntos.

Tales divergencias también han estado muy presentes en la instancia de debate internacional de Naciones Unidas. Así, cuando en ese contexto se arribó a la firma del Protocolo de Palermo, el documento final adoptó una definición de trata de personas que estuvo cargada de ambivalencias. De alguna manera, ellas expresaban la profunda dificultad con la que se construyeron los consensos tras una acalorada confrontación que protagonizaron los grupos feministas que participaron de ese debate (Varela, 2015).

La necesidad de sancionar nuevas legislaciones contra la trata de personas en nuestro país fue presentada desde el activismo antitrata bajo el argumento de solucionar un supuesto "vacío legal" existente en nuestro Código Penal, y con el propósito de dar mayor protección a las mujeres víctimas de explotación. ${ }^{6}$ Así, logró imponerse políticamente la reforma de nuestra legislación penal y ello dio lugar a un proceso de reconfiguración de la política criminal argentina que se cristalizó en las sucesivas modificaciones del Código Penal que produjeron las Leyes 26.364 de 2008, y 26.842 de 2012.

4 Los TIP Reports son un instrumento de evaluación construido por el Departamento de Estado de los EE.UU. que - desde sus propios estándares-justificaron la aplicación de sanciones económicas sobre aquellas naciones que no cumplían sus expectativas en la lucha contra la trata. Tal instrumento fue de fundamental importancia para la internacionalización de la campaña y el afianzamiento de intereses geopolíticos de los EE.UU. (Varela, 2015).

5 El (neo)abolicionismo es el resultado de un aggiornamiento del discurso feminista abolicionista de la prostitución (originalmente dirigido a combatir las prácticas disciplinarias de los regímenes reglamentaristas del siglo XIX) a las claves del pensamiento del feminismo radical estadounidense que define la sexualidad de las mujeres como el locus de la opresión y dominación masculina (Varela, 2020).

6 Sin embargo, desde el punto de vista dogmático, existen buenos argumentos para sostener que no existía tal vacío legal (Tarantino, 2020). 


\section{Las burocracias del rescate y la vulnerabilidad como llave de intervención criminalizante}

El nuevo marco legal y la intensificación de la campaña antitrata en el escenario político produjeron una transformación de las prácticas de las agencias penales en torno al sexo comercial. En efecto, los insumos teóricos que informaron estas prácticas plantearon la mirada (neo)abolicionista de la prostitución como la única postura que podía compatibilizar con nuestros compromisos internacionales, y especialmente con la flamante legislación penal contra la trata. De esta manera, la incorporación de esa particular perspectiva de género planteó una (re)interpretación de las diferentes formas de organización e intercambio de servicios sexuales, que pasaron a ser vistas como formas de explotación sexual.

El discurso psi construido desde las burocracias del rescate que brindan asistencia en los operativos judiciales contra la trata se convirtió en un saber experto que operó como factor clave de las definiciones judiciales sobre quiénes y cómo son las víctimas y los victimarios de este delito, y de qué manera las agencias penales debían abordar estos procesos con "perspectiva de género".

Sin embargo, la propia Titular del "Programa Nacional de Rescate y Acompañamiento a las Personas Damnificadas por el delito de Trata", Zaida Gatti, ha expresado públicamente que, del total de personas asistidas o rescatadas por este organismo, existe un $98 \%$ que no se reconoce como víctima (Trofelli, 2017). Tal contundente cifra encuentra explicación, precisamente, en la edificación de la categoría víctima como un a priori de estas intervenciones de rescate (Varela, 2020), y en la construcción del problema de la trata según esa ecuación binaria víctimas-victimarios a la que responde la idea de violencia de género con la que es pensada la prostitución.

Así, esta construcción del problema de la trata y la explotación sexuales responde al modo en que opera la categoría víctima en el dispositivo (neo)abolicionista; es decir, como un término despojado de todo anclaje en la autopercepción de los sujetos protagonistas (Varela, 2020).

En este sentido, también resulta paradigmática la perspectiva de Zaida Gatti cuando en una entrevista con Amnesty International manifestó:

Independientemente de que ellas [las personas que son prostituidas entrevistadas por la Oficina de Rescate durante los allanamientos] se presenten a sí mismas como personas que se dedican al "trabajo sexual autónomo", [lo que] se manifiesta [es] una situación de vulnerabilidad, una falta de elección y siempre, siempre, la presencia de una tercera parte que se lucra de la práctica de la prostitución de estas mujeres. Esto significa que existe un uso y abuso de tal situación. Por lo tanto, no es un trabajo libremente elegido, sino la única oportunidad que se les presenta. Entrevista de Amnistía Internacional a Zaida Gatti. (Amnesty, 2016: 18)

Esta incorporación del discurso (neo)abolicionista a las prácticas penales, en tanto "adecuada perspectiva de género y de derechos humanos", ha logrado instalar el dogma abolicionista por el cual la prostitución nunca es una verdadera opción autónoma. Es decir, con ello se ha logrado normativizar lo que, en realidad, es una perspectiva política que se remonta a los postulados del feminismo antipornografía de los años 70, y que ha sido motivo de una de las disputas más persistentes dentro de los feminismos (Lamas, 2016).

En este sentido, el especial protagonismo que adquirió la idea de vulnerabilidad como llave de apertura a las intervenciones rescatistas - y que opera por fuera de toda 
consideración de la capacidad de agencia de los sujetos a quienes se dirige-, se ha convertido en un dispositivo clave del gobierno de la trata y el trabajo sexual (Iglesias Skulj, 2017).

En definitiva, la amplia difusión del discurso antitrata en la escena pública, las reformas legislativas producidas y los desarrollos académicos que se ocuparon de su interpretación, así como los trabajos de incidencia institucional, han hecho posible que los postulados neoabolicionistas lograran dominar las prácticas de las agencias penales; $y$ lo hicieron a la manera de un saber experto que se legitimó como esa adecuada perspectiva de género y de derechos humanos que debían asumir lxs operadorxs del sistema penal.

De esta manera, lo que Varela (2013) llama laborinterpretante de las agencias judiciales, viene mostrando una especial incapacidad para alojar alguna trama de relaciones sociales, de trayectorias históricas o de formas heterogéneas de ejercicio del poder de agencia de las personas que hacen sexo comercial. La ausencia de una perspectiva política que dé cuenta de esta complejidad contribuye, además, a reforzar el eclipse de las voces de quienes no responden a una "auténtica" representación de la víctima.

La reconfiguración de la política antitrata en nuestro país - que incorporó e hizo suyos los postulados del (neo)abolicionismo- ha producido, entonces, que lxs operadorxs de las agencias penales solo puedan traducir las distintas posiciones de las personas en el mercado sexual, según la ecuación que gobierna la herramienta penal: victimas-victimarios. Ello repercute necesariamente en la ampliación del campo de criminalización del trabajo sexual, en especial sobre las terceras partes, esto es, aquellas personas que de algún modo contribuyen a la organización del trabajo sexual y que en buena medida son mujeres (trabajadoras sexuales o ex trabajadoras sexuales). Esto es lo que logra explicar el altísimo porcentaje de criminalización femenina por el delito de trata que ha mostrado esta política criminal de manera constante durante más de una década (Tarantino, 2019).

Develar el carácter político del enfoque de estas políticas, entonces, no es un asunto menor, puesto que tiene una estrecha relación con el impacto que han producido. Las investigaciones empíricas que se han ocupado de constatar ese impacto no son muy alentadoras: aumento de la clandestinidad de los intercambios de sexo comercial, profundización del estigma que padecen las trabajadoras sexuales, empeoramiento del acceso a sus derechos fundamentales (salud, vivienda, servicios sociales), incremento de la violencia institucional y sobrerrepresentación femenina en los procesos de criminalización por el delito de trata (AMMAR, 2014; Amnesty, 2016; Daich y Varela, 2014; Iglesias Skulj, 2017; Tarantino, 2019; entre otros).

\section{A modo de conclusión}

La discusión feminista en torno a cómo caracterizar el trabajo sexual es un problema eminentemente político; un debate histórico que ya tiene muchos años de antigüedad. Sin embargo, la institucionalización de los postulados neoabolicionistas, considerados como la única perspectiva de género que debe asumir la Justicia en el abordaje de los casos de trata de personas, ha ocultado el debate de los feminismos en torno a la prostitución; y, sobre todo, ha silenciado la voz de lxs trabajadorxs sexuales como sujetxs políticxs de ese debate.

Una reforma de la justicia merece, entonces, reflexionar sobre la experiencia que hemos recogido y sobre las herramientas que fuimos utilizando en el despliegue 
de este tipo de políticas criminales. Se trata de repensar nuestros marcos teóricos y poner en discusión la epistemología de nuestros procesos judiciales, de modo tal que logremos poner en el debate las categorías con las que construimos los problemas y que en no pocas ocasiones, al presentarse autoevidentes, obturan la posibilidad de una mirada sobre la complejidad y diversidad de las que están hechas las relaciones sociales y los conflictos que ingresan en el ámbito judicial.

Si queremos construir un sistema de justicia verdaderamente cercano a lxs protagonistas, que administre la conflictividad social de un modo más democrático y respetuoso de la pluraridad de puntos de vista, y que logre deconstruir las históricas posiciones de privilegio para develar las múltiples formas en que se manifiestan los factores de opresión, es necesario pensar de un modo más plural nuestros propios enfoques y prácticas. Acaso lo primero que quizá tengamos que hacer sea precisamente poner en debate de qué manera lograremos hablar en plural: cómo vamos a delinear, entonces, una nueva cultura judicial con perspectivas de géneros. 


\section{Bibliografía}

》 Agustín, L. (2009). Sexo y marginalidad. Emigración, mercado de trabajo e industria de rescate. Madrid, Popular.

"AMMAR (2014). Políticas antitrata yvulneración de derechos de las Trabajadoras Sexuales. Disponible en: http://www.ammar.org.ar/lMG/pdf/informe-ammar. pdf (último acceso 10/11/20).

»Amnesty International. (2016). Lo que hago no es un delito. El coste humano de penalizar el trabajo sexual en la Ciudad de Buenos Aires, Argentina. AMR 13/4042/16. Londres.

"Daich y Varela (2014). FALTA

"Doezema, J. (2010). Sex Slaves and Discourse Masters. The construction of Trafficking. Nueva York, Zed Books.

» Iglesias Skulj, A. (2017). ¿Cómo hacerse la sueca? Criminalización de la demanda de servicios sexuales: la gobernanza de la trata sexual en tiempos de feminismo punitivista. Revista Kula. Antropólogs del Atlántico Sur, № 17: 11-23. Buenos Aires.

»--------. (2018). La trata de personas en el contexto latinoamericano: La protección de los derechos humanos de las mujeres bajo un paradigma securitario. Especial referencia a México, Brasil y Argentina. Sistemas Judiciales. Una perspectiva integral sobre la administración de justicia. CEJA-INECIP, Género, diversidad sexual y Justicia, № 22, Buenos Aires.

»Lamas, M. (2016). Feminismo y prostitución: la persistencia de una amarga disputa. Debate Feminista, 5: 1-35, México, Programa universitario de Estudios de Género, Universidad Nacional Autónoma de México.

»Pitch, T. (2003 [1995]). Responsabilidades limitadas. Actores, conflictos y Justicia Penal. Buenos Aires, Ad Hoc.

»Tarantino, M. (2019). Trata de personas y criminalización femenina. Efectos no deseados de la campaña antitrata en Argentina. Revista Minerva. Saber, Arte y Técnica, № 3: 64-85.

"--------. (2020). ¿Qué hubo de nuevo en la legislación penal argentina contra la trata de personas? Un primer análisis de lo que nos dejaron las leyes 26.364 y 26.842. En Daich, D. y Cecilia V. (coords.). Los feminismos en la encrucijada del punitivismo, pp. 143-172. Buenos Aires, Biblos.

»Trebisacce, C. (2020). Un nacimiento situado para la violencia de género. Indagaciones sobre la militancia feminista porteña de los años 80. Anacronismo e Irrupción. Revista de Teoría y Filosofía Política Clásica y Moderna, Vol. 10, № 18: 118-138. Buenos Aires, Universidad de Buenos Aires.

»Trofelli, F. (2017). Zaida Gatti: Solo el 2 por ciento de las explotadas sexualmente se reconoce como víctima. Diario Tiempo Argentino, 11/02/2017.

"Varela, C. (2013). De la "letra de la ley" a la labor interpretante: la "vulnerabilidad" femenina en los procesos de judicialización de la ley de trata de personas (2008-2011). Cuadernos de Pagu [online], nº 41: 265-302. Campinas. 
” ---------------(2014) „Entre el combate a la trata y la criminalización del trabajo sexual: las formas de gobierno de la prostitución“, Revista Delito y Sociedad 38, año 23. 2do semestre.

»--------. (2015). La campaña antitrata en la Argentina y la agenda supranacional. En Daich, D. y Sirimarco, M. (coords.). Género y violencia en el mercado del sexo. Política, policía y prostitución. Buenos Aires, Biblos.

»--------. (2020). Tres paradojas en torno a las políticas antitrata. En Kostenwin, E. (dir.). El imperio de castigar. Contribuciones desde la sociología de la justicia penal. Buenos Aires, Editores del Sur. 